S. Jun, J. Lewis, D. Schwekendiek* (forthcoming), "Biological Living

Standards in Pre-Modern Chosŏn Dynasty Korea: Determinants of Height

of Militia Recruits", in: Economics \& Human Biology

\title{
The Biological Standard of Living in Pre-modern Korea: Determinants of Height of Militia Recruits During the Chosŏn Dynasty
}

\author{
Seong Ho Jun \\ The Academy of Korean Studies \\ James B. Lewis \\ University of Oxford \\ Daniel Schwekendiek* \\ Sungkyunkwan University
}

\begin{abstract}
This paper extends the research on the biological standard of living in the Korean peninsula back to pre-modern times. Drawing on militia rosters of the Chosŏn Dynasty from the sixteenth to eighteenth centuries, we tentatively conclude that the final height of Korean men during this period was $166 \mathrm{~cm}$ and thus slightly above that of modern North Korean men $(165 \mathrm{~cm})$. On the other hand, the average height of modern South Korean men is $172 \mathrm{~cm}, 6 \mathrm{~cm}$ more than what we tentatively estimate for pre-modern Korean men. Regression analysis of the height of pre-modern Korean men finds that un-free Koreans ("slaves") were significantly shorter by about 0.6 to $0.7 \mathrm{~cm}$ than commoners, whereas the average height of recruits suffering from smallpox did not differ significantly from that of other recruits. Moreover, regional, as opposed to birth-dummy, variables account, and to a significant degree, for most of the differences in height. Whether or not this is a result of socioeconomic differences across provinces or a result of other regionally-varying factors remains an open question.
\end{abstract}

Keywords: Chosŏn Dynasty, North Korea, South Korea, Asia, standard of living, height, anthropometric history, economic history

\section{JEL Classifications:}

I15, N15, N35

\section{Acknowledgements:}

James Lewis would like to thank the Academy of Korean Studies for a three-month Senior Fellowship (July to October 2012) that allowed him the time to gather data and confer with his colleagues. Daniel Schwekendiek is supported by the National Research Foundation of the Republic of Korea (NRF-2007-361-AL0014). 
S. Jun, J. Lewis, D. Schwekendiek* (forthcoming), "Biological Living

Standards in Pre-Modern Chosŏn Dynasty Korea: Determinants of Height

of Militia Recruits", in: Economics \& Human Biology

\section{Introduction}

The mean height of humans is a historical record of their net-nutritional experience (Komlos, 1995). Because human-growth status is the cumulative result of the quantity and quality of food consumed less the work load and the energy required to fight diseases, stature can be understood as an indicator of the biological standard of living (Baten and Wagner, 2003; Komlos and Kriwy, 2003; Moradi, 2010; Steckel, 2009). Most studies of the biological standard of living in Korea have focused on the twentieth century.

Schwekendiek and Jun (2010) investigated the secular height trend of South Korean men 20 to 40 years of age during the Cold War. Finding that final mean height increased dramatically in recent decades, they concluded that young South Korean men are the tallest in East Asia. Pak et al. (2011) investigated the anthropometric history of North Korea during the Cold War by making use of height measurements of North Korean refugees arriving in South Korea. They found that the height trend of both men and women in North Korea was one of stagnation, which they attributed to both the low quantity and the low quality of food consumed in the North. Focusing on the post-Cold War era, Schwekendiek and Pak (2009) and Schwekendiek (2009) and Pak (2004) highlight considerable growth deficits as a result of the North Korean famine of the 1990s.

Concerning earlier periods, Choi and Schwekendiek (2009) investigated height trends in Korea during the Japanese occupation (1910-1945). They show that the mean height of political prisoners 20 to 40 years of age from all social strata stagnated at $164-165 \mathrm{~cm}$. In a similar vein, Kim and Park (2011) investigated height measured during the Japanese occupation by analyzing reported heights of hangryu (haengnyŏ 行旅), or dead people without acquaintances and whose bodies therefore went unclaimed. The mean height of male hangryu 25 to 30 years of age was $159-161 \mathrm{~cm}$ : significantly less than that of male political prisoners born around the same time $(164-165 \mathrm{~cm})$. It should be noted, however, that this discrepancy may be due to the fact that the hangryu height measurements were of corpses of persons from the lowest socioeconomic stratum.

In another historical study, bone measurements from skeleton remains of the Chosŏn Dynasty (1392-1910) were assessed and height was recalculated in order to ascertain anthropometric changes spanning the length of the country's history, from pre-modern to modern times (Shin et al., 2012). Because birth cohorts could not be determined, the mean height of men was estimated at $161 \mathrm{~cm}$ for the entire period of the Chosŏn Dynasty. Moreover, sample sizes were small, with 67 men representing some 500 years.

While this research provides an estimate of the biological standard of living in pre-modern Korea, our data are based on measurements of male military conscripts. As discussed in Lewis et al. (2013), Korean academia has discussed these data for many years, but could not convert premodern height measurement units to modern centimeters. Whereas our previous research based on these data discussed methodological issues and descriptive analysis (Lewis et al., 2013), here our approach is primarily one of multivariate analysis. Along with the height measurements, we control for confounding socio-economic variables contained in the rosters (social status, province, birth period, and disease environment). Moreover, this paper makes further comparisons of pre-modern Korean male adolescents and adults with their modern South Korean and North Korean counterparts in order to investigate long-term changes in Korean stature.

\section{Data and Methods}

Confronted with devastating back-to-back Japanese invasions, collectively known as the Imjin War (1592-1596 and 1597-1598), the rulers of the Chosŏn Dynasty made military conscription of males compulsory for commoners (sangmin) and un-free persons (nobi, a designation sometimes translated as "slaves"). There was no official minimum height requirement for the militia..

Our earliest roster dates to 1596 and was thus constructed in the midst of the invasions, 
S. Jun, J. Lewis, D. Schwekendiek* (forthcoming), "Biological Living

Standards in Pre-Modern Chosŏn Dynasty Korea: Determinants of Height

of Militia Recruits", in: Economics \& Human Biology

making it one of the earliest of the newly introduced militia rosters and thus one of the earliest to have been survived in pre-modern times (Table 1). Conscription continued until the end of the Chosŏn Dynasty. Height was recorded in Korean 'feet', called ch'ǒk, and decimals, called ch'on. However, because height was no longer recorded in decimals after the roster of 1728 , we were obliged to exclude these later rosters from our anthropometric analysis. ${ }^{1}$ While the first roster was compiled in 1596 and the last reliable one in 1728, we were able to retrieve others, from 1679, 1685, and 1697 (Table 1). ${ }^{2}$ From each roster, we first collected height and age data; any entry that did not include both variables was declared invalid. Our sample sizes range from 121 individuals in 1728 to 895 individuals in 1697, with altogether 2,596 records for the observed period. ${ }^{3}$

We cannot be completely sure if the reported heights of the recruits were physically measured or just estimated. However, in all militia rosters we examined, there was a column for the Korean "feet" unit (ch'ók) and the decimal unit (ch'on). For instance, in the first roster from P'yŏng'an, 1 ch'on corresponds to about 2 centimeters, which is a relatively precise value that is unlikely to have been generated by visual inspection only. If the surveyors were only instructed to roughly estimate the height of recruits instead of physically measuring them, they would not have added a column for decimals (ch'on) to their records. Moreover, we argue that it would have been difficult if not impossible to estimate each recruit's decimal height than actually measuring them. All this suggests that individuals, which had decimals recorded, were most likely measured.

Table 1: Data sources

\begin{tabular}{lcccccc}
\hline Year & 1596 & 1679 & 1685 & 1697 & 1728 & TOTAL \\
\hline Province & P'yŏng'an & Ch'ungch'ŏng & Cheju & Ch'ungch'ŏng & Ch'ungch'ŏng & \\
N (age 20-40) & 375 & 379 & 826 & 895 & 121 & 2596 \\
N (age 13-19) & 107 & 85 & 342 & 267 & 39 & 840 \\
\hline
\end{tabular}

Source: Lewis et al. (2013).

We are primarily interested in the final heights of recruits 20 to 40 years of age, since measurements of this age group are unbiased by the catch-up growth that occurs during adolescence and the shrinking associated with old age, but we also calculate the height trend among the youngest recruits, 13 to 19 years of age. 2596 recruits were 20 to 40 years of age while 840 recruits were 13 to 19 years of age (Table 1). To compare the growth of pre-modern Korean adolescents with that of their modern-day peers, we compare our data to measurements of North and South Koreans.

We stratified individuals into four groups of 50-year birth cohorts: 1551-1600, 1601-1650, 1651-1700, and 1701-1750. The first of these four cohorts was born in the two Japanese invasions, of 1592-1598; the second cohort was born the effects, somewhat less dire, of the Manchu invasions of 1627 and 1636. The latter two cohorts was born in a relatively peaceful period.

The militia rosters examined here provide information on three regions: P'yŏng'an Province,

1 This disappearance of decimals in the later militia rosters may have been due to increased bureaucratic corruption combined with a long period of peace after 1636 (Second Manchu Invasion), making physical measurements unnecessary.

2 The rosters are discussed in Lewis et al. (2013). For 1596, see Chin'gwan kwanbyŏng yongmo ch'aek; see also Chin'gwan kwanbyŏng p'yŏn'o ch'aek chan'gwŏn 1, 2; for 1679, see Sukjong-dae Ch'ungch'ŏng-do sogo kunjŏk; for 1685, see Cheju sogo kunjŏkbu; for 1697, see Sukjong-dae Ch'ungch'ŏng-do sogo kunjŏk; for 1728, see Sukjong-dae Ch'ungch'ŏng-do sogo kunjŏk.

3 To calculate the recruits' birth years, we converted records that relate to Korean age classifications to common Western age by subtracting two years from the reported ages (one year has been subtracted because Koreans numerically advance in age with the Chinese lunar calendar instead of their individual anniversaries and another year has been subtracted because Koreans are traditionally one year of age at birth by default). Height, recorded in a local unit, $c h$ 'ók, was converted into centimeters by conducting a meta-analysis of extant Chosŏn Dynasty 'master' measuring sticks. The length of one ch'ók was estimated at $20.37 \mathrm{~cm}$. The analysis is explained in Lewis et al. (2013). 
S. Jun, J. Lewis, D. Schwekendiek* (forthcoming), "Biological Living

Standards in Pre-Modern Chosŏn Dynasty Korea: Determinants of Height

of Militia Recruits", in: Economics \& Human Biology

in the north; central Ch'ungch'ŏng Province; and Cheju Island, off the southern coast. The 1596 roster is from P'yŏng'an Province; at that time it stretched from around the city of P'yŏngyang (today the capital of North Korea) northwestward to the border with China at the Yalu River. The 1685 roster is from Cheju Island. The island diet has always been rich in marine protein, and the island was untouched by the two Japanese invasions of 1592-1598. The 1679, 1697, and 1728 rosters are all from Ch'ungch'ŏng Province, north of Chŏlla Province, to the southwest, and Kyŏngsang Province, to the southeast. Ch'ungch'ŏng Province lies to the south of the capital province of Kyŏnggi, where modern-day Sŏul (commonly transcribed as "Seoul"), the capital of the Chosŏn Kingdom as well as of today's South Korea, is located. Ch'ungch'ŏng Province (along with Kyŏngsang and Chŏlla Provinces) compose the Korean peninsula's rice bowl. Ch'ungch'ŏng Province sat on the interface between this rice bowl, to the south, and, to the north, a region of extensive dry-field (e.g., soybean) production. 


\section{Map 1: Provinces of the contemporary Korean peninsula}

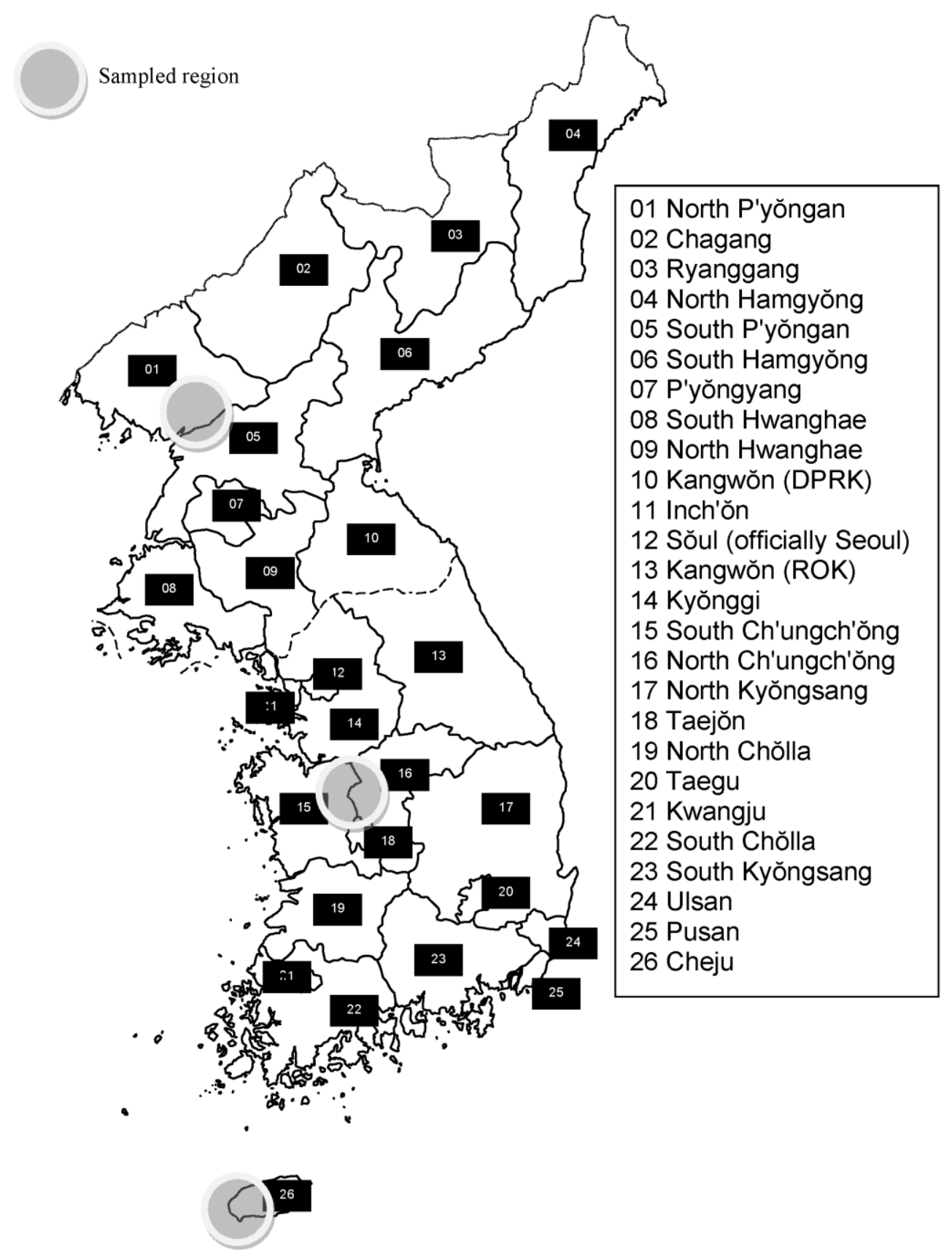


S. Jun, J. Lewis, D. Schwekendiek* (forthcoming), "Biological Living

Standards in Pre-Modern Chosŏn Dynasty Korea: Determinants of Height

of Militia Recruits", in: Economics \& Human Biology

About $48 \%$ of the conscripts were unfree; roughly the same ratio of unfree to free persons (commoners) made up the non-aristocratic population of the Chosonn Dynasty as a whole. Along with the conscripts' social status, distinguishing facial features were recorded in the rosters. Height was probably measured to assess an individual's capacity for physical combat. Also, height is an identification feature that makes it easier to track deserters. It is likely that facial features were also recorded for purposes of subsequent identification. These records of facial features serve an unintended purpose of providing us with a valuable detail regarding the conscripts' disease history, in that they include mention of smallpox scars (pak / champak, or 縛 / 暫縛 ). Individuals who did not have facial smallpox scars represent the reference category. ${ }^{4}$ Heintel and Baten (1998) did not find that smallpox had an impact on height.

\section{Findings}

We performed seven regression analyses of pre-modern Koreans between the ages of 20 and 40 in regard to socio-economic variables (Table 2). All heights are represented in Models 1, 3, 5, and 6, whereas rounded heights of $8.0 \mathrm{ch}$ 'ŏk (or about $163 \mathrm{~cm}$ ) are excluded from Models 2, 4, and 7. As seen in the Appendix (Figures 1 to 3), there is height heaping around $8.0 \mathrm{ch}$ 'ók. The reason for this may be that, since 8.0 was the standard, expected height of pre-modern Korean men (Lewis et al., 2013), conscripts appearing to have such a standard height were probably not measured and estimated.

All birth-period dummy variables are statistically insignificant (Models 1 and 3). Cohorts born during the period affected by the Imjin War 1551-1600)were significantly shorter (by more than $3.3 \mathrm{~cm}$ ) than those born in the later period of general peace (1701-1750), but the coefficient is statistically insignificant (Models 1 and 3). However, when rounded heights are eliminated from the calculation, the results indicate that the recruits born during the Japanese invasion were on average strikingly shorter, by more than $10 \mathrm{~cm}$, than those in the other birth cohorts (Models 2 and 4). Whether this difference is due to a selection bias (i.e., taller Koreans were already systematically recruited in the first wave of invasion starting in 1592), a result of the devastating environmental effects of the Japanese invasion, or otherwise indicative of difficult living standards in the latter part of the sixteenth century cannot be clarified here.

On the other hand, all province dummies are statistically significant (Models 1, 3, and 5). More importantly, the size effect is enormous: Cheju recruits were some 7 to $11 \mathrm{~cm}$ taller while P'yŏng'an recruits were some 6 to $10 \mathrm{~cm}$ shorter than recruits from the reference category (Ch'ungch'oung Province). That Cheju recruits were found to be relatively tall is explained by several factors: the island was untouched by the Japanese invasions; the islanders enjoyed a relatively high standard of living probably thanks to the local fishing industry and distance from disease vectors; ${ }^{5}$ and recruits seem to have been selected for height $\left(8 \mathrm{ch}{ }^{\prime} \breve{o k}\right){ }^{6}{ }^{6}$ Likewise, it is not surprising that P'yŏng'an recruits were much shorter than their counterparts from Ch'ungch'ŏng Province, since

4 Individuals with scars caused by measles (i.e., not by smallpox) are included in the reference category.

5 In 1792, King Chŏngjo undertook a survey to count the number of people of 90 years and older. If we take this survey as a proxy for the quality of life as exhibited in life expectancy, then Cheju comes at the top and we can rank the various provinces by the ratio of over 90 -year olds to total population: Cheju $(0.10 \%)$, Kangwŏn $(0.07 \%)$, Hwanghae (0.06\%), Kyŏnggi (0.04\%), Ch'ungch'ŏng (0.03\%), Chŏlla (0.03\%), Kyŏngsang (0.03\%), P'yŏng'an (0.03\%), and Hamgyŏng (0.02\%). Ilsŏngnok, Chŏngjo 16 (1792.06.18).

6 A statistical comparison of populations from the 1789 Hogu ch'ongsu shows that Cheju was probably the most selective if we accept that a smaller percentage of the male populace in the military rosters would indicate higher selection. With this measure, the provinces can be ranked for possible selectivity: Cheju (18\%), Hamgyŏng (20\%), Kangwŏn (22\%), Kyŏngsang (23\%), P'yŏng'an (24\%), Ch’ungch’ŏng (27\%), Chŏlla (30\%), Kyŏnggi (33\%), and Hwanghae (40\%). 
S. Jun, J. Lewis, D. Schwekendiek* (forthcoming), "Biological Living

Standards in Pre-Modern Chosŏn Dynasty Korea: Determinants of Height

of Militia Recruits", in: Economics \& Human Biology

Ch'ungch'orng represented the rice bowl of the Korean peninsula, and its inhabitants therefore benefited from a relatively high-calorie and nutritious diet, whereas the P'yŏng'an recruits were less advantaged. Note that further technical explanations for these regional variations will be discussed in the last section of this paper.

Slaves were significantly shorter than free commoners, by about $0.6 \mathrm{~cm}$ (Model 3). On the other hand, two studies in which relatively high socio-economic status was proxied by tertiary education reveal an interesting discrepancy: among middle- and lower-class South Korean men, height was not directly correlated with class (Schwekendiek and Jun, 2010), whereas twenty-first century upper-class North Korean men were found to be 1 to $2 \mathrm{~cm}$ taller than middle- and lowerclass North Korean men (Pak, et al., 2011). ${ }^{7}$ This discrepancy suggests that in pre-modern Korea there was little variation according to socio-economic class in the biological standard of living, whereas in contemporary North Korea there was a direct correlation between nutritional intake and class level. However, since our data exclude the ruling, aristocratic class (yangban), which constituted from 5\% to $20 \%$ of the pre-modern Korean population (from before 1600 up to around 1730), ${ }^{8}$ and concern only the middle (sangmin) and lower (nobi) classes, further studies using yangban data are needed to corroborate, or not, as the case may be, our results.

In regard to disease environment, the smallpox dummy variables are not statistically significant in all models. Smallpox in England has been reported to have had a significant negative effect (of at least one inch) on height (Voth and Leunig, 1996). A re-analysis, involving some technical adjustments, of the same data by a different pair of researchers indicated that smallpox has no such impact on height (Heintel and Baten, 1998), the result of which is corroborated here. The dummy for interaction between socio-economic status and disease environment is insignificant as well (Model 3). However, when rounded heights are removed, both the interaction dummy and the smallpox coefficient are statistically significant. Model 5 has been added to control for the possibility of shortfall in height resulting from the apparent rounding of heights of shorter recruits as well as to account for possible selection biases (Figures 1 to 3). We ran a truncated regression with a lower limit of $6.99 \mathrm{ch}$ 'ók (or about $142 \mathrm{~cm}$ ). Model 5 corroborates Model 4, although slaves were now found to be somewhat shorter (by $0.67 \mathrm{~cm}$ ) than before (by $0.55 \mathrm{~cm}$ ).

\footnotetext{
Height gaps by educational status were, however, plotted only in the case of South Korea. As the height trends among South Koreans of various educational levels overlapped, the study's authors concluded that social differences as indicated by height were insignificant in South Korea thanks to government-sponsored food as well as milk programs throughout the school system.

8 It is difficult to estimate the makeup of the Chosŏn period population, because we have detailed data only from parts of Kyŏngsang Province, which show that yangban may have been around $10 \%$ in 1690 , rising to around $20 \%$ by the 1730 s and to $50 \%$ by 1800 . See Kim, Nobi, p. 158 . The difficulty of determining who was actually yangban remains a problem, and these figures were reported in the Japanese colonial period. Research is still on-going, and we await more accurate estimates. Our last data source is 1728, and none of our data sources come from Kyŏngsang Province, which was a southern "yangban-rich” area of the country. If we had similar data from the north, such as P'yŏng'an Province, the percentage of yangban would probably have been smaller than $20 \%$.
} 
S. Jun, J. Lewis, D. Schwekendiek* (forthcoming), "Biological Living

Standards in Pre-Modern Chosŏn Dynasty Korea: Determinants of Height of Militia Recruits", in: Economics \& Human Biology

Table 2: OLS and truncated pooled regression of final heights of pre-modern Korean men

\begin{tabular}{|c|c|c|c|c|c|c|c|}
\hline & $\begin{array}{c}\text { All } \\
\text { heights } \\
(1) \\
\end{array}$ & $\begin{array}{l}\text { No ' } 8.0 \text { ' } \\
\text { heights } \\
(2) \\
\end{array}$ & $\begin{array}{c}\text { All } \\
\text { heights } \\
(3) \\
\end{array}$ & $\begin{array}{c}\text { No '8.0' } \\
\text { heights } \\
(4)\end{array}$ & $\begin{array}{c}\text { All } \\
\text { heights, LL } \\
(5) \\
\end{array}$ & $\begin{array}{c}\text { All } \\
\text { heights } \\
(6) \\
\end{array}$ & $\begin{array}{c}\text { No '8.0' } \\
\text { heights } \\
(7)\end{array}$ \\
\hline (Constant) & $163.92^{\star *}$ & $165.15^{\star \star}$ & $164.23^{\star \star}$ & $165.73^{\star *}$ & $164.86^{\star \star}$ & $161.77^{\star \star}$ & $164.45^{\star \star}$ \\
\hline \multicolumn{8}{|l|}{ Birth period } \\
\hline Born 1551-1600 & -3.33 & $-10.37^{\star}$ & -3.47 & $-10.95^{\star}$ & -4.15 & $-11.84^{\star *}$ & $-16.03^{* *}$ \\
\hline Born 1601-1650 & 0.93 & 3.90 & 0.69 & 3.26 & 0.23 & $4.49^{* *}$ & $8.07^{* *}$ \\
\hline $\begin{array}{l}\text { Born } 1651-1700 \\
\text { Born } 1701-1750 \text {, ref. }\end{array}$ & 0.14 & 3.10 & -0.03 & 2.58 & -0.30 & $5.16^{\star *}$ & $8.57^{\star *}$ \\
\hline \multicolumn{8}{|l|}{ Province } \\
\hline Cheju & $10.80^{* *}$ & $7.37^{* \star}$ & $11.14^{\star *}$ & $8.12^{* *}$ & $10.91^{* *}$ & & \\
\hline $\begin{array}{l}\text { P'yŏng'an } \\
\text { Ch'ungch'ŏng, ref. } \\
\text { Social status }\end{array}$ & $-10.43^{\star \star}$ & -6.31 & $-10.28^{\star \star}$ & -5.95 & $-10.25^{\star \star}$ & & \\
\hline $\begin{array}{l}\text { Slave }(\text { yes }=1) \\
\text { Epidemiology }\end{array}$ & & & $-0.55^{\star}$ & -0.89 & $-0.67^{*}$ & $3.13^{\star *}$ & $1.13^{* *}$ \\
\hline $\begin{array}{l}\text { Smallpox }(\text { yes }=1) \\
\text { Interaction }\end{array}$ & & & 1.16 & $4.85^{*}$ & 0.86 & -0.98 & 0.56 \\
\hline Slave $\times$ Smallpox $($ yes $=1)$ & & & -0.57 & $-4.55^{\star}$ & 0.74 & $-3.88^{*}$ & $-5.89^{* *}$ \\
\hline Adj. R sq. & 0.55 & 0.61 & 0.55 & 0.61 & - & 0,37 & 0.56 \\
\hline $\mathrm{N}$ & 2559 & 1461 & 2486 & 1390 & 2440 & 2486 & 1390 \\
\hline
\end{tabular}

Note: ${ }^{* * *}$ significance at the $10 \% / 5 \%$ level, LL = lower-limit truncation (at 6.99 ch'ǒk, or about $142 \mathrm{~cm}$ ).

We determined the consistency of our estimated trend by comparing it with the baseline-model specifications (Models 6 and 7). Because the birth-cohort dummies and province dummies are multicollinear, deleting the province dummies from the regression reveals that Koreans born during the Imjin Wars (1592-1598) are significantly and strikingly shorter $(12 \mathrm{~cm})$ than those born during peacetime (after 1700). Moreover - although the interaction dummy is significant (except for Model 3) - the effect of smallpox remains insignificant. Furthermore, these results indicate that the slaves are significantly and strikingly taller, by 1 to $3 \mathrm{~cm}$, than free commoners (Models 6 and 7): the opposite of the results in Models 3 to 5. Because the province and birth-cohort variables are multicollinear, there is no way to disentangle the two effects (birth-year dummies vs. province dummies). The finding of Margo and Steckel (1982) that free blacks were slightly taller than unfree blacks in antebellum Virginia corroborates the results in Models 3 to 5; we therefore do not summarize the results in Models 6 and 7. Further studies are needed to test their validity.

Final-height distributions by province are shown in the Appendix (Figures 1 to 3). The fact that in the height histogram for P'yŏng'an Province there is no truncation on the left indicates that there were indeed no minimum requirements, since the militia but not the military recruits were measured (Figure 1). However, the fact that there is a slight heaping on the right side of the distribution, suggests that a maximum value was automatically assigned to these taller recruits. Since the P'yŏng'an roster was constructed during the back-to-back Japanese invasions, there was an urgent need for information that would facilitate the identification of those recruits best suited for assignment to the special (heavier) weapon classes: hence the heaping of taller recruits in that sample. The relative absence of height heaping on the right side in the other rosters, which were constructed during peacetime, supports the interpretation that recruits were being selected for heavier weapons (Figures 2 
S. Jun, J. Lewis, D. Schwekendiek* (forthcoming), "Biological Living

Standards in Pre-Modern Chosŏn Dynasty Korea: Determinants of Height

of Militia Recruits", in: Economics \& Human Biology

and 3). This means that height in the rosters of P'yŏng'an Province would have been greater if the individual measurements of the taller recruits had been recorded; that they were not may account in part for the fact that P'yŏng'an recruits were recorded as being shorter than those of the other two provinces, but it does not explain that the mode and median is around 7.6 ch'ók (Figure 1). We therefore suggest that the aforementioned regional differences may account for most of the height gaps between P'yŏng'an Province and Cheju Island and Ch'ungch'ŏng Province, although further technical biases are discussed in the conclusion.

Because of apparent upper- and lower limit heaping, we performed six additional truncated regressions for P'yŏng'an Province (upper-limit truncation at 8.0 ch'ŏk or about $163 \mathrm{~cm}$ ), Cheju Island (lower-limit truncation at 8.49 ch'ŏk or about $173 \mathrm{~cm}$ ), and Ch'ungch'ŏng Province (lower-limit truncation at 7.99 or about $163 \mathrm{~cm}$ ), where we excluded rounded heights (Table 3). Because of missing values, all that we can control for is social status. Slave status proves to be insignificant (Table 3) in all the OLS regression and the truncated regression (Model 1 to 4), with the exception of Ch'ungch'óng Province (Model 5 and 6) where slave status is significantly negative. 
S. Jun, J. Lewis, D. Schwekendiek* (forthcoming), "Biological Living

Standards in Pre-Modern Chosŏn Dynasty Korea: Determinants of Height

of Militia Recruits", in: Economics \& Human Biology

Table 3: OLS and truncated separate regression of final heights of pre-modern Korean men

\begin{tabular}{|c|c|c|c|c|c|c|}
\hline & $\begin{array}{l}\text { P'yŏng'an } \\
\text { All heights }\end{array}$ & $\begin{array}{c}\text { P'yŏng'an } \\
\text { All heights, UL }\end{array}$ & $\begin{array}{c}\text { Cheju } \\
\text { All heights }\end{array}$ & $\begin{array}{c}\text { Cheju } \\
\text { All heights, LL }\end{array}$ & $\begin{array}{l}\text { Ch'ungch'ǒng } \\
\text { All heights }\end{array}$ & $\begin{array}{l}\text { Ch'ungch'ǒng } \\
\text { All heights, LL }\end{array}$ \\
\hline & (1) & (2) & (3) & (4) & (5) & (6) \\
\hline (Constant) & $148.66^{\star \star}$ & $148.95^{* \star}$ & $175.54^{* \star}$ & $177.18^{* \star}$ & $170.25^{* \star}$ & $155.47^{* *}$ \\
\hline \multicolumn{7}{|l|}{ Social status } \\
\hline 1) Slave (yes = & -0.12 & -0.13 & 0.39 & -0.26 & $-0.39^{* *}$ & $-12.45^{* *}$ \\
\hline $\mathrm{N}$ & 319 & 319 & 743 & 508 & 356 & 274 \\
\hline
\end{tabular}

We calculated the height distribution of recruits from Ch'ungch'ong Province and of Cheju Island recruits (Figures 2 and 3, respectively) - but, Cheju recruits were much taller than their P'yŏng'an and Ch'ungch'ŏng Province peers. They were almost as tall as modern Koreans (Table 4). Although we maintain that living conditions on the island were better than those elsewhere in the country, sampling biases in that dataset could explain these regional gaps.

To compare the growth of pre-modern Koreans with that of their modern-day peers, we compare our data to measurements published by Pak (2010) in the mid 2000s of adolescents in North and South Korea. For adults, we refer to Pak (2004), who reported the heights of North Korean men in the 20 to 39 age range. The mean height of pre-modern Korean men, $166 \mathrm{~cm}$ (Table 4), was $1 \mathrm{~cm}$ greater than that of modern North Korean men (Tables 4 and 5). This finding indicates that the biological standard of living in North Korea has slightly declined to below the level of the $17^{\text {th }}$ century. Moreover, the final height of men born in modern South Korea - an OECD country since 1996 - was $172 \mathrm{~cm}, 6$ to $7 \mathrm{~cm}$ taller than that of men of the Chosŏn Dynasty.Not surprisingly, across all age cohorts North Korean adolescent recruits were significantly shorter than their South Koreans counterparts, while pre-modern adolescents who were 15 to 19 years of age were shorter than North Korean recruits in the same age bracket.However, the mean height gap by age group between premodern and North Korean recruits is small, perhaps because pre-modern Korean adolescents enjoyed a better standard of living than do modern North Korean adolescents (Table 5). The fact that South Korean adolescents are strikingly taller than both their pre-modern and their modern North Korean peers is in line with the finding in regard to the relative heights of adults, with South Korean adults considerably taller than adults in the other two categories, in which there is no noticeable final-height difference (Table 4). Because Korean ethnicity has been exceptionally homogenous for centuries, genetic population differences are effectively ruled out.

Table 4: Comparison of final heights of pre-modern Korean men with those of modern North and South Korean men

\begin{tabular}{|c|c|c|c|}
\hline & $\begin{array}{l}\text { Premodern Korean men } \\
\text { (this study) }\end{array}$ & $\begin{array}{l}\text { North Korean men measured } \\
\text { in the twenty-first century }\end{array}$ & $\begin{array}{c}\text { South Korean men } \\
\text { measured in the twenty-first } \\
\text { century }\end{array}$ \\
\hline Age & Mean & Mean & Mean \\
\hline
\end{tabular}


S. Jun, J. Lewis, D. Schwekendiek* (forthcoming), "Biological Living

Standards in Pre-Modern Chosŏn Dynasty Korea: Determinants of Height

of Militia Recruits", in: Economics \& Human Biology



Note: The North and South Korean figures relate to a 20-39 age group, whereas the pre-modern figures relate to the heights of Korean men 20 to 40 years of age. Mean values of modern North and South Koreans were calculated from reported group averages.

Source: Table 1, Korean Agency for Technology and Standards (2004), Pak (2004).

Table 5: Comparison of heights of pre-modern Korean adolescent males with those of North and South Korean adolescent males

\begin{tabular}{|c|c|c|c|c|c|c|c|c|c|}
\hline \multirow[b]{2}{*}{ Age } & \multicolumn{3}{|c|}{$\begin{array}{l}\text { Pre-modern Korean } \\
\text { adolescent males } \\
\text { (this study) }\end{array}$} & \multicolumn{3}{|c|}{$\begin{array}{l}\text { North Korean adolescent } \\
\text { males measured in the } \\
\text { twenty-first century }\end{array}$} & \multicolumn{3}{|c|}{$\begin{array}{l}\text { South Korean adolescent } \\
\text { males measured in the } \\
\text { twenty-first century }\end{array}$} \\
\hline & $\mathrm{N}$ & Mean & SD & $\mathrm{N}$ & Mean & SD & $\mathrm{N}$ & Mean & SD \\
\hline 13 & 92 & 151.4 & 15.1 & 47 & 143.3 & 9.8 & 269 & 158.2 & 7.6 \\
\hline 14 & 68 & 157.2 & 13.1 & 60 & 148.4 & 9.7 & 253 & 164.7 & 7.4 \\
\hline 15 & 124 & 153.3 & 15.6 & 55 & 156.2 & 9.4 & 276 & 169.2 & 5.9 \\
\hline 16 & 134 & 156.6 & 13.1 & 68 & 159.7 & 8.2 & 254 & 170.3 & 5.8 \\
\hline 17 & 97 & 158.4 & 13.6 & 73 & 160.7 & 7.7 & 269 & 172.5 & 5.5 \\
\hline 18 & 160 & 161.9 & 12.2 & 70 & 163.7 & 6.0 & 266 & 172.9 & 5.5 \\
\hline 19 & 165 & 160.8 & 12.7 & 68 & 164.8 & 4.9 & 277 & 173.4 & 5.6 \\
\hline
\end{tabular}

Note: The ages of the North and South Korean adolescents were measured using .49 cut-offs instead of the standard .99 cut-offs.

Source: Table 1, Pak (2010).

\section{Conclusion}

Analyzing final height of pre-modern Korean men using regression analysis, we find that un-free Koreans ("slaves") were significantly shorter - by about 0.6 to $0.7 \mathrm{~cm}$ - than commoners, while the height of recruits suffering from smallpox did not differ significantly from that of other recruits. Moreover, regional, but not birth-period, dummies account to a considerable degree for the differences in height.

Some shortcomings of this study are that our estimated mean height of pre-modern Korean men $(166 \mathrm{~cm})$ can possibly be biased by truncation and rounding to a heaped height. A recent osteometric study suggests that the mean height of pre-modern Korean men was $164.59 \mathrm{~cm}$ (Pak 2011). This indicates that our mean height of 166 centimeter is slightly overestimated probably due to technical issues. Another likely explanation for these differences could be that our birth periods differ from those of Pak (2011), since the skeleton remains used in the osteometric study could not be dated.

Further technical biases could arise from regionally varying measuring sticks. Although lengths of measuring sticks were regulated by the king by sending 'master' measuring sticks to every frontier pass, county office, garrison, and post station, local people continued to use their own 'modified' measuring sticks as these sticks were used for trade (i.e., to commit commercial fraud). Lewis et al. (2013) conducted a meta analysis of extant 'master' measuring sticks to proxy the conversion rate of pre-modern Korean ch'ók into modern centimeters, but they assume that the surveyors either used an official one (usually made out of metal) or an unofficial one (usually made out of wood) that was a good copy of the 'master'. It cannot be ruled out that some surveyors might have applied a local measuring stick instead of a 'standard' one. This could likewise explain some of the regional variations in height that were detected here.

In addition to this, we also suggest that selection bias could have accounted for many of the regional variations in height. While P'yŏng'an recruits were mostly shorter because they were recruited in the midst of the Imjin War (as explained above, the tallest recruits were most likely already drafted at the beginning of the invasion), Cheju Island recruits were 
S. Jun, J. Lewis, D. Schwekendiek* (forthcoming), "Biological Living

Standards in Pre-Modern Chosŏn Dynasty Korea: Determinants of Height

of Militia Recruits", in: Economics \& Human Biology

possibly taller because they were selected for their height in accordance with an old prescription from the fifteenth century for regular army selection: recruits should be at least eight ch'ók tall. ${ }^{9}$ The finding that we see some truncation on the right in the P'yŏng'an Province roster as well as the fact that most militia recruits from Cheju Island were $8.0 \mathrm{ch}$ 'ók or taller (which in turn was exactly the minimum height for the regular, standing army) corroborates this. The fact that there were more than twice as many recruits from Cheju Island as compared to P'yŏng'an Province (Table 1), suggests that our mean height of $166 \mathrm{~cm}$ is over- rather than under-estimated.

Whereas previous studies of the biological standard of living in Korea focused on North Korea, South Korea, and Korea during the Japanese occupation (1910-1945), the scope of this paper extends as far back as the mid- $16^{\text {th }}$ century. Drawing on Chosón Dynasty militia rosters, we conclude that the final mean height of pre-modern Korean men was $166 \mathrm{~cm}$, slightly superior to that of modern North Korean men but $6 \mathrm{~cm}$ inferior to that of their South Korean counterparts. North Korean adolescents 15 to 19 years of age were found to be slightly taller than their pre-modern peers, and both of these groups were found to be shorter than their South Korean peers.

\footnotetext{
$9 \quad$ Sejong sillok 99: 11b-12a (1443.2.3) and Sejong sillok 102:17b-18a (1443.11.2).
} 
S. Jun, J. Lewis, D. Schwekendiek* (forthcoming), "Biological Living Standards in Pre-Modern Chosŏn Dynasty Korea: Determinants of Height of Militia Recruits", in: Economics \& Human Biology

\section{Appendix}

Figure 1: Final height distribution of P'yŏng'an Province

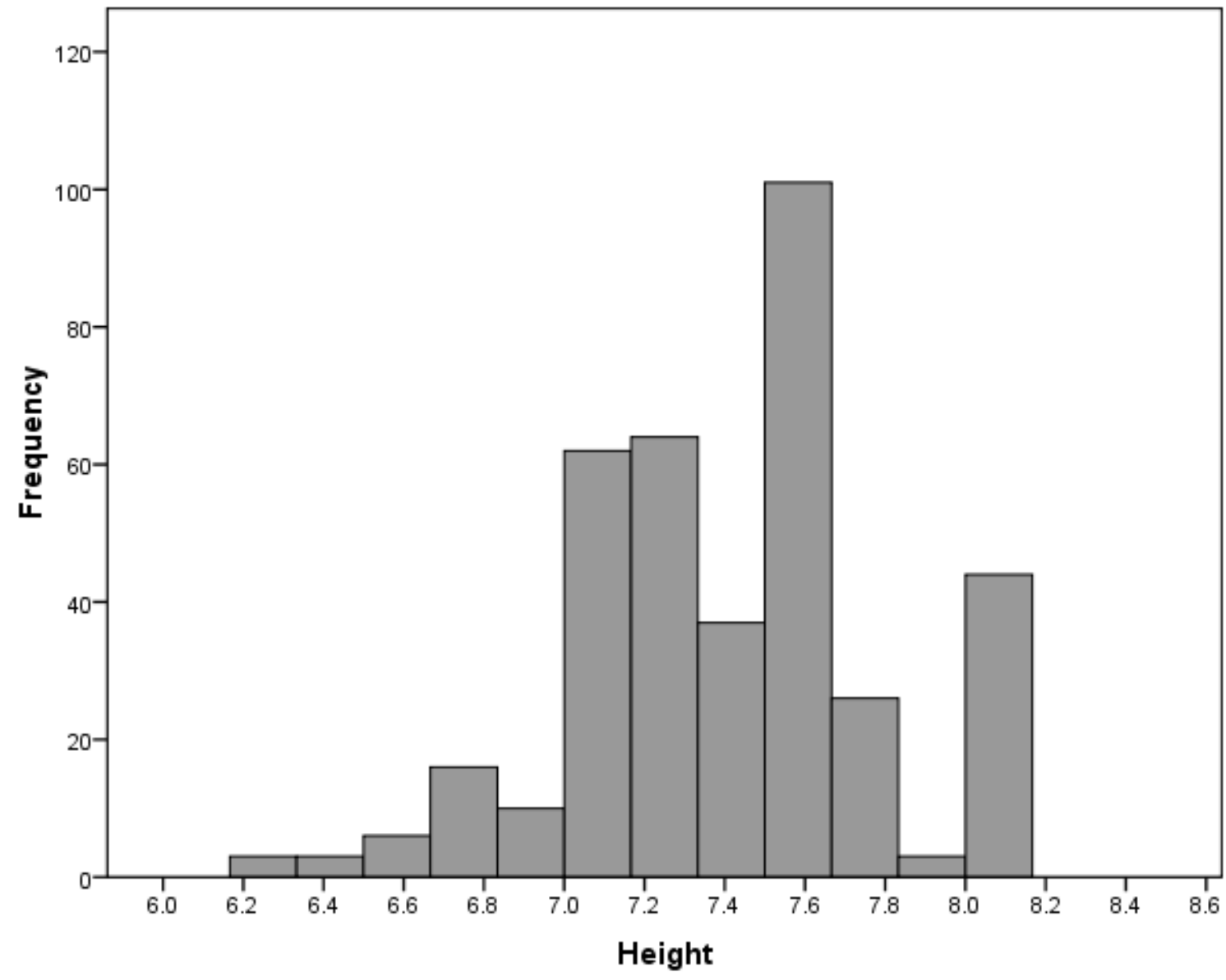

Notes: Heights are given in Korean units (ch'ǒk). The conversion method is discussed in Lewis et al. (2013). Shown are the terminal heights of 20 to 40 year old men coming from P'yŏng'an Province. 
S. Jun, J. Lewis, D. Schwekendiek* (forthcoming), "Biological Living Standards in Pre-Modern Chosŏn Dynasty Korea: Determinants of Height of Militia Recruits", in: Economics \& Human Biology

Figure 2. Final height distribution of Ch'ungch'ŏng Province

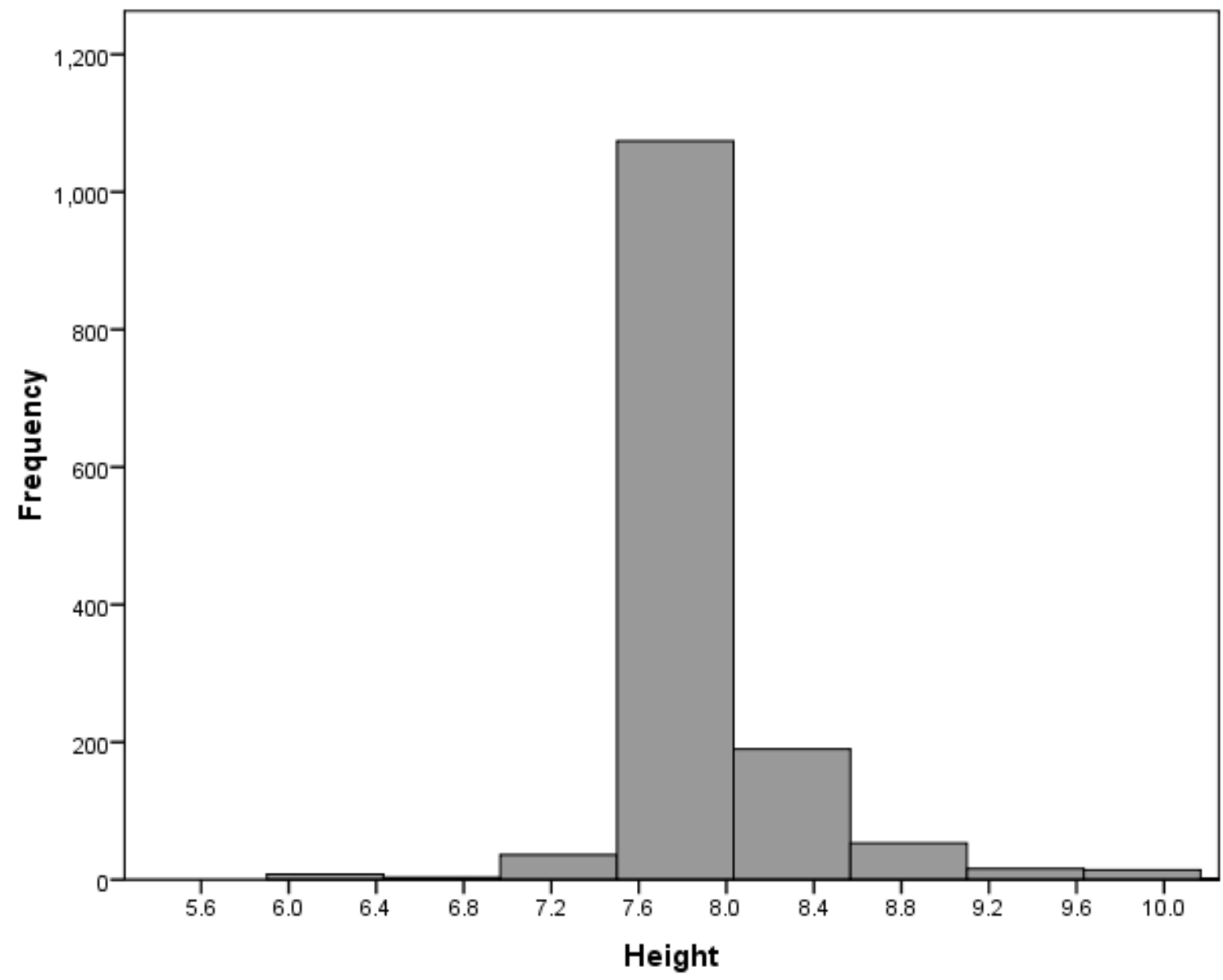

Notes: Height in Korean units (ch'ŏk). The conversion method is discussed in Lewis et al. (2013). Shown are the terminal heights of 20 to 40 year old men coming from Ch'ungch'ǒng Province. 
S. Jun, J. Lewis, D. Schwekendiek* (forthcoming), "Biological Living Standards in Pre-Modern Chosŏn Dynasty Korea: Determinants of Height of Militia Recruits", in: Economics \& Human Biology

Figure 3: Final height distribution of Cheju Island

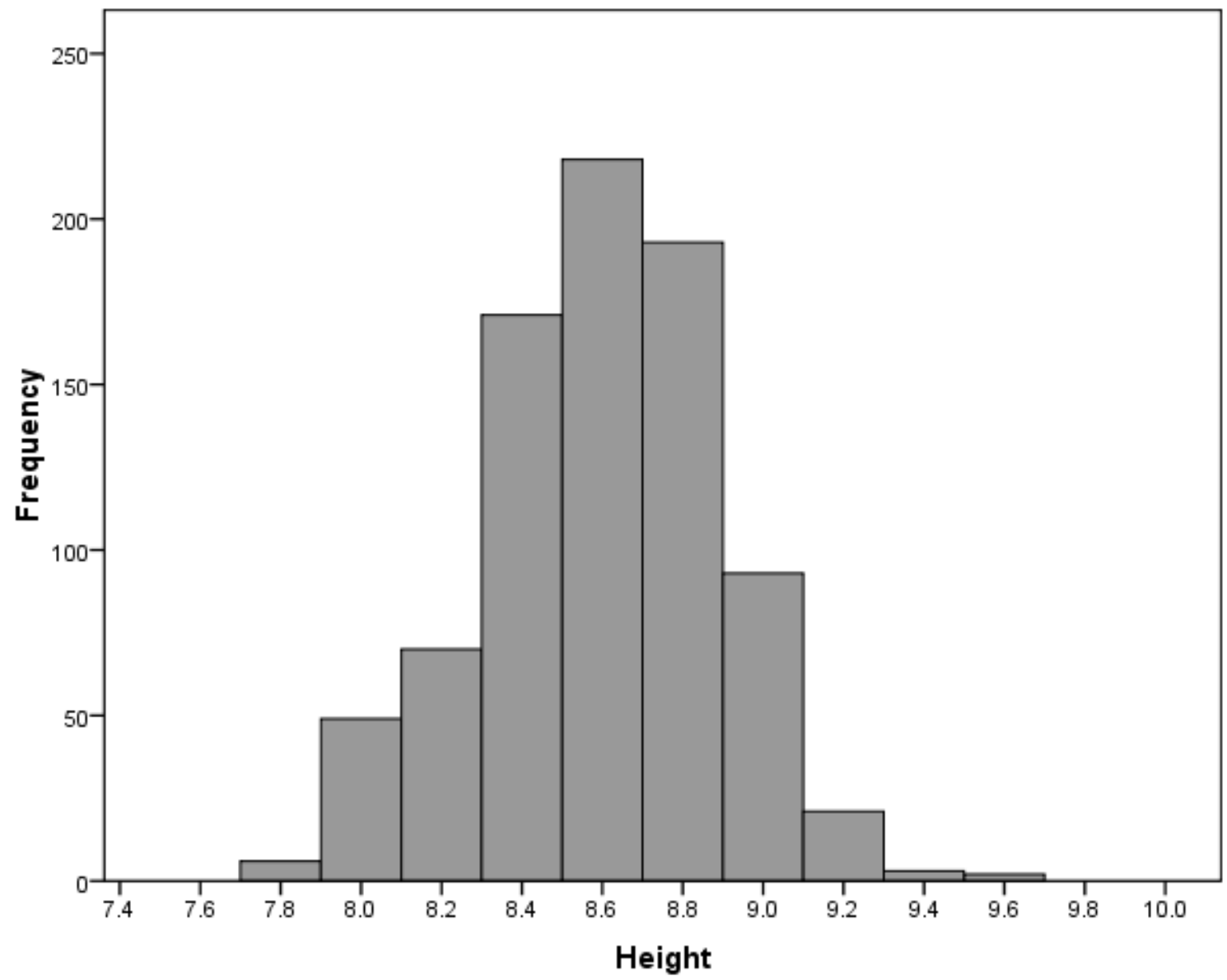

Notes: Height in Korean units (ch'ŏk). The conversion method is discussed in Lewis et al. (2013). Shown are the terminal heights of 20 to 40 year old men coming from Cheju Island. 
S. Jun, J. Lewis, D. Schwekendiek* (forthcoming), "Biological Living

Standards in Pre-Modern Chosŏn Dynasty Korea: Determinants of Height

of Militia Recruits", in: Economics \& Human Biology

\section{References}

Baten, Jörg, Wagner, Andrea, 2003. Autarchy, market disintegration, and health: The mortality and nutritional crisis in Nazi Germany 1933-1937. Economics and Human Biology 1, 1-28.

Choi, Seong-Jin, Schwekendiek, Daniel, 2009. The biological standard of living in Colonial Korea, 1910-1945. Economics and Human Biology 7, 259-264.

Heintel, Markus, Baten, Joerg, 1998. Smallpox and Nutritional Status in England, 1770-1873: On the Difficulties of Estimating Historical Heights. Economic History Review, 51, 360-371.

Hogu ch'ongsu (Aggregate Census) 戶口總數, 1789.

Ilsŏngnok (Chronicle of Daily Affairs) 日省錄, 1752-1910.

Kim, Bok Rae, 2004. Nobi: A Korean System of Slavery. In Campbell, Gwyn, ed. Structure of Slavery in Indian Ocean Africa and Asia. London: Frank Cass, 153-165.

Kim, Duol, Park, Heejing, 2011. Measuring living standards from the lowest: height of the male Hangryu deceased in colonial Korea. Explorations in Economic History 48, 590599.

Komlos, John, 1995. The Biological Standard of Living on Three Continents: Further Explorations in Anthropometric History. Westview Press, Boulder, San Francisco, Oxford.

Komlos, John, Kriwy, Peter, 2003. The biological standard of living in the two Germanies. German Economic Review 4, 459-473.

Korean Agency for Technology and Standards, 2004. Report on the Fifth Size Korea National Anthropometric Survey. KATS, Gwachon (in Korean).

Lewis, James B., Jun, Seong Ho, Schwekendiek, Daniel, 2013. Toward an Anthropometric History of Chosŏn Dynasty Korea, Sixteenth to Eighteenth Century. Journal of the Historical Society 13, pp. 239-270.

Margo, Robert A., Steckel, Richard H., 1982. The Heights of American Slaves: New Evidence on Slave Nutrition and Health. Social Science History 6, 516-538.

Moradi, Alexander, 2010. Nutritional status and economic development in sub-Saharan Africa, 1950-1980. Economics and Human Biology 8, 16-29.

Pak, Sunyoung, 2004. The biological standard of living in the two Koreas. Economics and Human Biology 2, 511-521.

Pak, Sunyoung, 2010. The growth status of North Korean refugee children and adolescents from 6 to 19 years of age. Economics and Human Biology 8, 385-395.

Pak, Sungyoung, 2011. An Estimation of Adult Males' Average Stature from the Skeletal Remains of Joseon Period. Korean Journal of Physical Anthropology 11, 185-193.

Pak, Sunyoung, Schwekendiek, Daniel, Kim, Hee Kyoung, 2011. Height and living standards in North Korea, 1930s-1980s. Economic History Review 64, 142-158.

Schwekendiek, Daniel, 2009. Height and weight differences between South and North Korea. Journal of Biosocial Science 41, 51-57.

Schwekendiek, Daniel, 2014. The Data Atlas of South Korea: Demography, Society, Economic Activity. Jimoondang Publisher, Paju, Seoul, Edison.

Schwekendiek, Daniel, Jun, Seong-Ho, 2010. From the poorest to the tallest in East-Asia:

The secular trend in height of South Koreans. Korea Journal 50, 151-175.

Schwekendiek, Daniel, Pak, Sunyoung, 2009. Recent growth of children in the two Koreas: A meta-analysis. Economics and Human Biology, 7, 109-112.

Sejong sillok (King Sejong’s Veritable Records) 世宗實錄 1418-1450.

Shin, Dong Hoon, Oh, Chang Seok, Kim, Yi-Suk, Hwang, Young-il 2012. Ancient-to- 
S. Jun, J. Lewis, D. Schwekendiek* (forthcoming), "Biological Living Standards in Pre-Modern Chosŏn Dynasty Korea: Determinants of Height of Militia Recruits", in: Economics \& Human Biology

Modern Secular Changes in Korean Stature. American Journal of Physical Anthropology 147, 433-442.

Steckel, Richard, 2009. Heights and human welfare: Recent developments and new directions. Explorations in Economic History 46, 1-23.

Voth, Hans-Joachim, Leunig, Timothy, 1996. Did Smallpox Reduce Height? Stature and the Standard of Living in London, 1770-1873. Economic History Review 49, 541-560. 